\title{
Fuels Management at the Landscape Scale
}

\section{By Sherman Swanson and Wendell Gilgert}

\section{Introductory Focus by Featured Speakers}

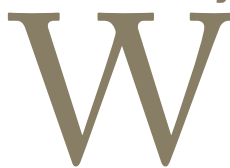

orkshop IV was moderated by Brad Washa, Bureau of Land Management (BLM). Jason Davison of the University of Nevada Cooperative Extension spoke about a "Case Study of the Murphy Complex Fire." A team of scientists and managers ${ }^{1}$ had been charged to 1 ) provide preliminary observations and recommendations on how plant communities and livestock grazing affected fire behavior, 2) recommend long-term research or studies needed to address issues regarding the use of livestock to reduce fuels while maintaining post-fire resource values, and 3) discuss the potential application of the findings from the Murphy Complex wildfires in Idaho and Nevada to other locations. After identifying many areas with high discontinuity and contrast, the team evaluated each area using 10 factors: 1) actual use by livestock, 2) distance from water, 3) anomaly performance (related to pasture actual grazing pressures in grassland areas), 4) fire history, 5) location of seedings, 6) vegetation type, 7) shrub cover, 8) cheatgrass cover, 9) prefire plant biomass, and 10) fire behavior/suppression. They ranked burn severity factors across all focus areas and across grass-dominated areas. Vegetation (fuel loads) was the most

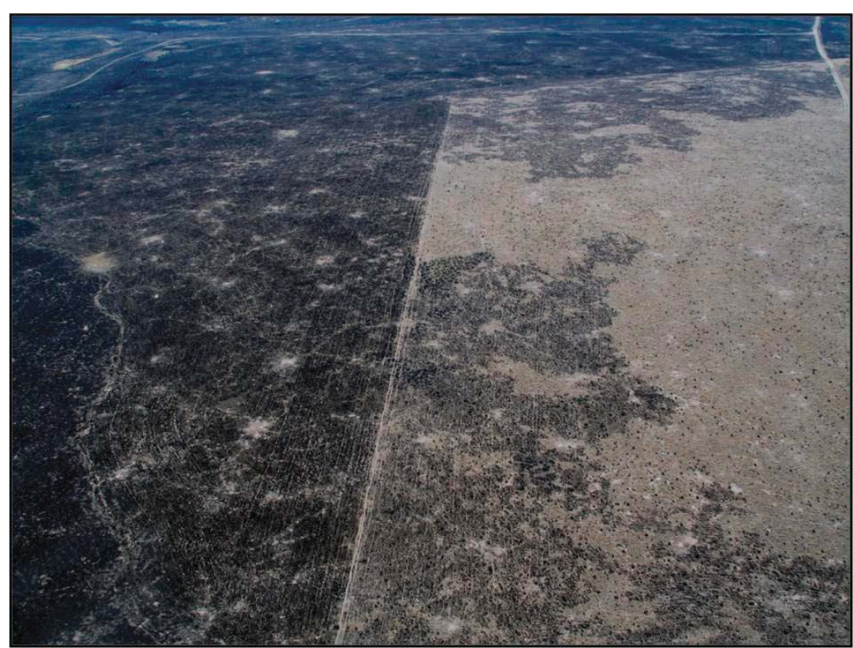

Air photo from a small part of the Murphy Complex Fire showing a fence-line contrast between a black ungrazed seeding (left) and a mosaic grazed seeding. (Photo from slide show by Jason Davison, University of Nevada, Reno, Fallon, Nevada) important factor affecting burn severity. Grazing effects increased in grassland systems and decreased as shrub cover increased. While post-fire determinations of grazing impacts were difficult at best, additional large-scale research on grazing/fire behavior is needed.

"Managing the Invasive Fine Fuels at the Landscape Scale" was presented by Ronald Clementsen, BLM, who reported on the Mojave Desert Initiative (MDI). The MDI was established as a forum for government agencies (BLM, National Park Service [NPS], US Fish and Wildlife Service [USFWS], Department of Defense, Nevada Department of Wildlife, Utah Department of Wildlife Resources, and Arizona Game and Fish Department) and other partners to collaboratively address wildfire and invasive species issues within a defined eco-region of the northeastern Mojave Desert in Arizona, Nevada, and Utah. Their goals are to 1) protect remaining unburned Mojave Desert vegetation and reduce reburning; 2) restore strategically located islands, key habitat areas, and corridors; 3) improve communication, collaboration, and coordination; and 4) maximize leveraged funding. They developed regional priorities and guidance for incident commanders to minimize or avoid further habitat loss to fire. They also completed regional assessment to identify priority work areas and to develop project selection criteria. High-density, unburned desert tortoise critical habitat is their first priority for protection and restoration. It is followed by unburned critical habitat for all listed species (not included in priority one) within BLM National Conservation Areas, BLM and NPS monuments, NPS recreation areas, and USFWS refuges. They will identify, prioritize, and develop potential projects across the MDIdefined-eco-region, including fuel breaks, green-strips, seedings, plantings, applications of preemergent herbicide, etc.

Robin Tausch, US Forest Service (USFS) Rocky Mountain Research Station, addressed "Fuels Management Strategies for Woody Natives to Avoid Promoting Invasive Species." Using data from research projects in Nevada, Utah, Idaho, and Oregon, Robin showed the remarkable increase in the area, cover, size, and density of pinyon pine and juniper. These trees are changing plant communities in many areas of the western United States. Once established, 


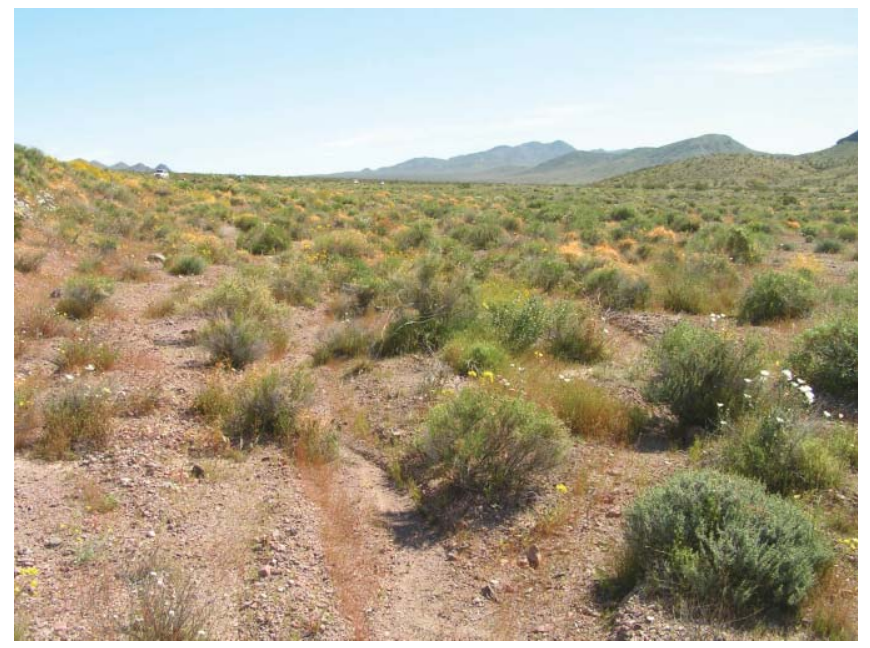

In heavy precipitation years, the Mojave Desert now produces abundant annual grasses along with the exceptional spring bloom. (Photo by Sherman Swanson, Department of Natural Resources and Environmental Science, Reno, Nevada)

they continue to grow and increase their dominance while outcompeting the understory and increasing fuels for fires. As the trees come to occupy about $60-70 \%$ of the current canopy cover for the site, they have largely removed the understory biomass, yet tree biomass and fuels continue to increase. Thereafter, a dramatic shift in the response of the understory follows prescribed fire or wildfire because the site has crossed a threshold to another state. Post-fire understory vegetation increases its composition of bunchgrasses if the trees burn before reaching the threshold, whereas competition and heat from the fire kill the perennials and create a wide-open niche for annual grasses and mustards once the threshold is crossed. Because trees established in prior

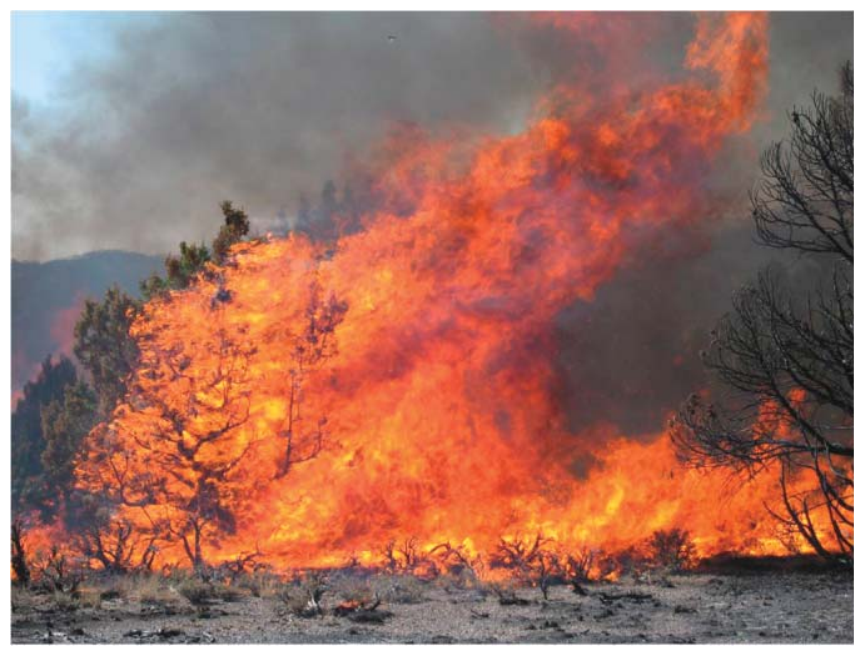

Intense heat from burning pinyon-juniper trees that have increased in size and density beyond a threshold finishes the creation of large bare areas that invite invasives because they have become devoid of perennial vegetation. (Photo by Robin Tausch, USDA Forest Service, Rocky Mountain Research Station, Reno, Nevada) decades continue to grow, nearly 200,000 acres (81,000 ha) of the Intermountain West cross this threshold annually.

"Breaking Through Roadblocks to Implementation: Policies that Create or Solve Problems" was about Restore New Mexico and presented by Jesse Juen, Associate State Director, BLM New Mexico. Restore New Mexico is an aggressive partnership to restore woodlands, grasslands, and riparian areas to a healthy and productive condition. $860,000+$ acres (350,000 ha) have been treated since 2005, and 5 million additional acres ( 2 million ha) are identified for future treatments to 1) curtail the expansion of invasive plant species (mesquite, creosote, juniper, and salt cedar); 2) improve water quality and quantity; 3) reduce impacts from catastrophic wildfire; 4) restore habitat for fish, wildlife, and endangered species; and 5) defragment habitat from historic oil and gas development. To achieve those objectives, they work with various partners to assess, plan, treat, monitor, and adjust their approach. Rangeland health assessments are used to determine and prioritize treatments. Their goal, to meet or exceed standards, leads to a toolbox of techniques and strategies to treat/restore impacted areas while maintaining healthy lands. They recognize that restoration takes time and they let results speak for themselves in order to generate enthusiasm. They collaborate to create innovation and streamline implementation using all tools available. To encourage communication and cooperation among disciplines within the BLM, as well as to address budget or workload issues, they focused first on highly motivated offices to demonstrate success. They convened interdisciplinary teams with meetings of the right players for project planning at the appropriate scale. They also let everyone "own" accomplishments, claim success, tell the story, and show what they are doing with field visits for potential partners and critics. They recommend 1) a passionate point person, 2) an integrated focus of all programs to meet their goals, 3) using geospatial technology, 4) maintaining flexibility to shift funds to achieve the "biggest bang-for-the-buck," 5) writing landscape-level environmental assessments, 6) applying risk models (such as Rangeland Ecological Assessments) to help make decisions, 7) agreeing to promote multijurisdictional action, 8) using creative contracting mechanisms, 9) rewarding over-performance, 10) using fire funding for restoring landscapes, and 11) developing candidate conservation agreements to bypass single-species issues.

The panel discussion, "Overcoming Obstacles to Fuels Management at the Landscape Scale," addressed questions about Restore New Mexico and woodland expansion. The costs to treat rangeland shrubs varied from US $\$ 15-20 /$ acre (\$37-50/ha) with fire, to $\$ 26-32 /$ acre $(\$ 65-80 / h a)$ with herbicides. Tamarisk removal costs $\$ 200 /$ acre (\$500/ha) using a combination of mechanical, chemical, and/or fire treatments. Treatment costs to the producers, including forgone animal unit months (AUMs), are being offset by funding from the oil and gas industry. They are willing to pay to see land improvement. Ranchers, too, are happy to see the land improve and have not received additional 


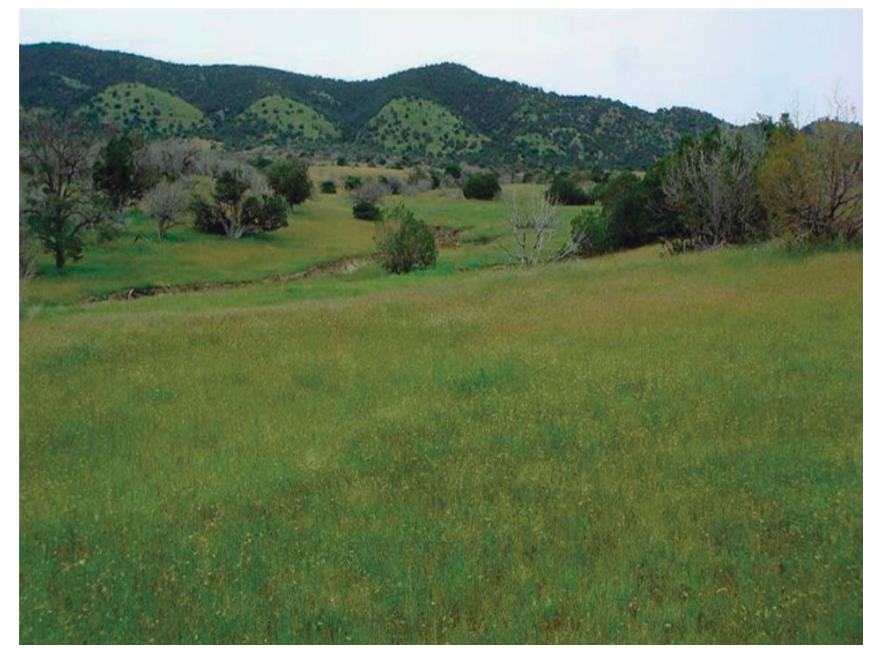

Restore New Mexico seeks to curtail the expansion of invasive plant species (mesquite, creosote, juniper, and salt cedar); improve water quality and quantity; reduce impacts from catastrophic wildfire; restore habitat for fish, wildlife, and endangered species; and defragment habitat from historic oil and gas development. (Photo from slide show by Jesse Juen, Bureau of Land Management, New Mexico State Office, Sante Fe, New Mexico)

AUMs after project successes. Although the BLM does not currently have grass banks, the idea has been discussed, as was the concept of using guilds of plant species for assessing project effects. There has been a roughly 30-million-acre (12-million-ha) increase in the area classified as woodland across the Great Basin during the last 150 years.

\section{Audience Input}

"Management and Policy" was the focus of most of the participants in the audience. Many commented about livestock management alternatives, addressing how livestock grazing can reduce fuel loading, particularly in grass and shrub communities. It seems clear to some that without grazing to reduce fine fuels, we might lose sagebrush as a component of many Intermountain landscapes. One commenter noted (presumably about the Murphy Complex fire) that litigation had caused grazing use to be limited to $15 \%$ of current year's growth, which led to a large buildup of fine fuels with a 2-3-year carryover of residual fuels. Cheatgrass (Bromus tectorum L.) fuels ensured the demise of sagebrush.

Using a variety of tools for animal control, grazing could be used to strategically keep fuel loads from accumulating in fuel breaks. One respondent noted that Derek Bailey (of New Mexico State University) used global positioning systems to map cattle behaviors; however, the tools he used have yet to find their way into best management practices for the Environmental Protection Agency, Natural Resources Conservation Service, BLM, USFS, and USFWS. Another summarized that "We need new and innovative methods to manage livestock behavior, and [we need to] communicate these techniques to the general public." Perhaps addressing the need for economic incentives, one participant cautioned that contracts for prescribed grazing miss the point if it is assumed that meat production will pay for the contract performance. Alternatively, we should advertise for competitive bidding for contract-based prescribed grazing, especially for young entrepreneurs, and then ensure that successful bidders meet contract specifications.

Cheatgrass increases during the 2 years of mandated rest from grazing following a fire, when management is justly focused on perennials. Alternatively, grazing management immediately following a fire could target emergence of cheatgrass in the spring, with only brief and light grazing thereafter to restore vigor of perennial grasses. Grazing differently after cheatgrass heads turn purple is just one example of developing prescriptions for grazing to protect areas from fire while focusing on desired future conditions.

Because residual fuels carry over, many big fires happen following several wet years. Fall grazing of temporary nonrenewable forage is a way to 1) harvest this fuel, 2) graze when bunchgrasses are dormant (not vulnerable) and no more nutritious or palatable than cheatgrass, and 3) graze in the fall when spring-calving cattle have low nutritional needs. Adequate cattle performance can be maintained with protein supplementation.

Better fire models are needed to more completely understand how fuel reduction treatments in the sagebrush ecosystem affect ecosystem health and plant succession. Funding would be needed to maintain preferred wildfire frequencies (possibly with fire surrogates), evaluate effects, and update land management plans. It is critically important to manage fuel levels without increasing invasive species.

To address changing climate (presumably because of increased risk of larger fires and fires with consequences detrimental to storage of soil carbon), there is a need to exponentially increase the number of fuels projects of all types, biological, mechanical, fire, and chemical. Carbon sequestration could be evaluated by focusing on underground soil carbon from root turnover, $\mathrm{CO}_{2}$ emissions from fires, and loss of photosynthetic uptake of carbon following fire.

Some audience responses reiterated the importance of responding to pinyon and juniper $(\mathrm{PJ})$ encroachment before losing herbaceous species, and to "raise the alarm about Great Basin PJ fuel increases before they cross a particular threshold." Robin Tausch's data demonstrate increased costs and loss of resource values including forage, habitat, watershed protection, resistance to invasive weeds, etc., after transitioning to plant communities lacking native perennials. For vegetation management, it helps to choose areas that provide the highest probability of success. If tree growth has progressed past threshold levels, perhaps PJ trees could be thinned to regain understory plants before further treatment. However, the root systems of nearby trees can be extensive, leading to large interspaces between trees where vegetation is absent. Tree-dominated stands nearing a threshold are candidates for biofuels harvesting, and this could subsidize the costs of projects for managing these ecosystems. A more holistic approach would often address 
PJ increases before fuels accumulate to a level interesting to biofuels harvesters. Funds that would eventually have to be spent for post-fire restoration could address accumulating fuels. Large old PJ trees in previously fire-safe sites can be protected by surrounding them with resilient vegetation producing only short flame lengths.

Many in the audience advocated "working at the landscape scale," decreasing the continuity of fuels using landscape-scale planning with interagency maps of vegetation types that are fire resistant and fire resilient. Education to seek the support of top level managers for landscape-scale National Environmental Policy Act (NEPA) analysis and management can be encouraged by rewarding managers for using landscape scales to integrate management approaches rather than simply quantifying the number of acres treated. Within agencies, the lines could be blurred if emergency stabilization and rehabilitation and fuels funding could both create greenstrips (fuel breaks vegetated by fire resistant plants).

Ecological studies employing landscape approaches could be used to manage vegetative spatial dynamics to prevent catastrophic-sized fires. This would involve managing patch size and the arrangement of patches to limit the continuity of fuels. Should we reduce the size of shrub or woodland patches and add fuel breaks, rather than remove all trees across broad areas? Managers could use strategic placement of fuels treatments at the landscape scale to balance woodlands and sagebrush to keep fuel loads in check. Achieving optimum success may require more fire use and more tools or risk, such as prescribed burning in Haines index 6, if blacklines or fuels breaks are in place. To keep rangeland ecosystems resilient with limited funds, it will be necessary to prioritize the use of funds and communicate with the public why some areas are more intensely managed than others.

"Collaboration and interdisciplinary planning" was emphasized by many participants to incorporate multiple benefits and work across boundaries. To promote projects that manage fuels while enhancing wildlife habitat and other multiple use goals, engaging federal land managers and the public to establish landscape restoration is a priority. The expertise available could be broadened by early and frequent involvement of multiple partners in interdisciplinary planning. Restore New Mexico is an excellent model that overcame restrictive policies, lack of funding, and turf battles with communication from state directors that established priorities. It is a positive example that grows the tool box, including candidate conservation agreements for lesser prairie chickens (Tympanuchus pallidicinctus). The Healthy Lands Initiative also requires significant cooperative management of many natural resources.

Many also felt that federal agencies should participate in broad landscape-scale restoration as a standard operating procedure. An agency could address management by considering current vegetation condition (forage, habitat, biofuels, etc.), values, and potential for restoration, regardless of jurisdictional boundaries. To deal with multiple ownerships, federal resources could be spent on nonfederal lands. To identify risks to a landscape, it is necessary to work across ownership lines. Because there are many different demands for resources across a landscape, teams need to include multiple agencies and public interests working with focused managers who engage all parties in collaborative efforts. There is also a need for flexible funding. To augment cooperation among land managers and private entities, planning approaches with long planning horizons should be used to develop and implement plans. They should then be assessed and monitored over the long term, and projects phased in, to ensure continuity.

One person noted that "vegetation manipulation is one of the toughest ideas to sell to the public, and healthy rangelands by themselves are not enough." However, many noted the value of science-based collaborations to create public support. The public's perspective improves when consensusbuilding creates partnerships that include even the most vocal critics. Involving the public as a partner and pooling funding for large-scale projects can inspire the public to support the NEPA process and avoid litigation. Public support at the federal level can carry over to state and community projects too. Integrating disciplines to educate the public about fuels management also helps efforts for long-term weed control.

"Assessment and monitoring with objectives and adaptive management" focused many audience responses. People wanted to achieve better landscape-scale assessments of resource conditions, but they also valued site-specific information for plan modifications. For example, they recommended using ecological sites to prescribe fire, observed that large-scale treatments often conflict with management prescriptions, and advocated making decisions on the ground. They suggested measureable objectives and targeting areas that are at-risk. For example, to set objectives, one could make maps of departure from reference conditions. However, this does not necessarily lead to at-risk areas or to treatments timed for before costs rise. Pace of work across a landscape could be defined as an objective, but usually objectives address time by including a timeline of expected treatments and continuing vegetation changes for key areas. With objectives for a focus, monitoring-with research when needed-can objectively track the information needed to adapt management through time. Effective monitoring requires dedicated personnel time and a consistent protocol.

"The wildland-urban interface (WUI)" was recognized as a frontline for recent investments. In strategic areas close to development, the need for food, fiber, etc. can be included by grazing WUI fuels for payment, so long as the land remains healthy. Local fire departments can promote defensible space with ordinances and inspections that emphasize personal responsibility of the homeowner. This enables land management agencies to focus on ecosystem management. 
For example, land managers can focus on juniper management for ecological benefit, not just hazardous fuels on the WUI. In general, we will only be able to address the broader landscape if we move the fuels program from a local emphasis towards ecosystem protection. To address WUI fuels issues, we might use a cost-share basis to help homeowners remove fuels.

Audience participation focused on funding, communicating with the public, and directions for future research. Some suggested innovative contracting approaches to get clearances for NEPA and archeological surveys. Funding ideas expressed by participants focused on encouraging collaboration and allowing federal resources to be spent on nonfederal lands. This would better integrate management across areas with multiple types of land ownership. Combining fuels projects with wildlife habitat improvement goals for multiple benefits would promote funding, which is needed to stay ahead of the wildfire interval. Some suggested it would be helpful to be able to carry funds over from one year to the next to sustain funding across uneven funding years. The use of innovative contracting might stretch work forces or boost marginal projects. For example, fuels removed too far from markets may require a subsidy for biofuels.

Outreach priorities and science recommendations serve as a summary of some of the more important points raised by the audience.

- Determine the nature of irreversible thresholds favoring transitions of plant communities and soils toward invasive plants.
- Focus research on rapid and effective tools to address the urgency of the problem.

- Determine landscape dynamics affecting fire in desert landscapes.

- Develop grazing methods to protect areas from catastrophic wildfire and reduce fuel loading, particularly where remnant perennials grow with invasive annuals.

- Determine the effects of fuels management on sagebrush ecosystems, invasive species, and ecosystem health.

\section{References}

1. Launchbaugh, K., B. Brammer, M. L. Brooks, S. Bunting, P. Clark, J. Davison, M. Flemming, R. Kay, M. Pellant, D. Pyke, And B. Wylie. 2008. Interactions among livestock grazing, vegetation type, and fire behavior in the Murphy Wildland Fire Complex in Idaho and Nevada, July 2007. Reston, VA, USA: USGS Open-File Report 2008-1214. 42 p.

Authors are University of Nevada State Extension Rangeland Management Specialist and Rangeland and Riparian Scientist, Dept of Natural Resources and Environmental Science, 1000 Valley Rd, Reno, NV 89512, USA, sswanson@cabr.unr.edu (Swanson); and West Region Wildlife Biologist, USDA Natural Resources Conservation Service, West National Technical Support Center, 1201 NE Lloyd Center, Suite 900, Portland, OR 97232, USA, wendell.gilgert@por.usda.gov (Gilgert). 